Portland State University

PDXScholar

Environmental Science and Management

Faculty Publications and Presentations

$10-1-1990$

\title{
Third-generation FAGE instrument for tropospheric hydroxyl radical measurement
}

\author{
C. Y. Chan
}

Portland State University

Thomas M. Hard

Portland State University

\author{
A. A. Mehrabzadeh \\ Portland State University \\ Robert J. O'Brien \\ Portland State University
}

Follow this and additional works at: https://pdxscholar.library.pdx.edu/esm_fac

Part of the Environmental Indicators and Impact Assessment Commons, and the Environmental Monitoring Commons

Let us know how access to this document benefits you.

\section{Citation Details}

Chan, C. Y., Hard, T. M., Mehrabzadeh, A. A., George, L. A., and O'Brien, R. J. (1990). Third-generation FAGE instrument for tropospheric hydroxyl radical measurement. Journal Of Geophysical Research, 95(D11), 18569-18576.

This Article is brought to you for free and open access. It has been accepted for inclusion in Environmental Science and Management Faculty Publications and Presentations by an authorized administrator of PDXScholar. Please contact us if we can make this document more accessible: pdxscholar@pdx.edu. 


\title{
Third-Generation FAGE Instrument for Tropospheric Hydroxyl Radical Measurement
}

\author{
C. Y. Chan, T. M. Hard, A. A. Mehrabzadeh, L. A. George, and R. J. O’Brien \\ Chemistry Department and Environmental Sciences and Resources Program, Portland State University, Portland, Oregon
}

\begin{abstract}
We have constructed a single-stage, frequency-doubled, copper vapor laser-pumped dye laser to be used in the measurement of atmospheric hydroxyl radical concentrations. This laser can be tuned to either the $1 \leftarrow 0$ or $0 \leftarrow 0$ vibrational transition in the electronic transition ${ }^{2} \Sigma \leftarrow^{2} \Pi$. A new photon counting instrument is used for HO fluorescence detection. Theoretical and experimental studies of instrument performance show better sensitivities and reduced photolytic interferences than have been possible with previous systems based upon Nd:YAG pumping.
\end{abstract}

\section{INTRODUCTION}

In the measurement of tropospheric $\mathrm{HO}$ we have employed two low-pressure laser-excited fluorescence (LEF) experimental systems [Hard et al., 1984, 1986, also FAGE measurements of tropospheric HO: Ambient data, interference measurements, and model, submitted to Journal of Geophysical Research, 1990 (hereinafter referred to as submitted manuscript, 1990)]. These instruments operated by expanding the ambient air flow via a nozzle, followed by transit down a flow tube through a detection region traversed by the excitation laser beam. This sampling method we named FAGE (fluorescence assay with gas expansion). Both instruments employed a hydrocarbon reagent, added below the nozzle, to remove HO for background measurement. In the second instrument, air sampling via two parallel nozzles and tubes, with reagent addition alternating between the two channels, permitted continuous signal measurement with simultaneous measurement of background.

The first-generation instrument [Hard et al., 1984], referred to here as FAGE1, employed a low-power, $6-\mathrm{Hz}$ repetition rate Nd:yttrium aluminum garnet (Nd:YAG) laser and a dye laser of our own construction. Subsequently, with FAGE2 [Hard et al., 1986, submitted manuscript (1990)], we used a $30-\mathrm{Hz}$ commercial Nd:YAG/dye laser system for ambient measurements. In both cases, Nd:YAG pumped systems were chosen for their practical availability. However, the low pulse repetition frequency (prf) and higher energy per pulse of Nd:YAG-pumped systems are not ideally suited for ambient HO measurements, because of the potential for production of spurious $\mathrm{HO}$ by laser photolysis of atmospheric HO precursors. Since a higher-prf laser of comparable power is better suited for these measurements, we have developed a third-generation HO instrument (FAGE3) based upon a $5.6-\mathrm{kHz} \mathrm{Cu}$ vapor pump laser. After dye pumping and frequency doubling, this laser maintains an average energy comparable with that of our Nd:YAG pumped system, with the advantage of lower energy per pulse.

Spreading the available pumping energy out over a larger number of pulses has several benefits. Foremost of these is

Copyright 1990 by the American Geophysical Union.

Paper number 90JD01619.

0148-0227/90/90D-01619\$05.00 greatly reduced transient saturation of the photomultiplier tube (PMT) by leakage of the excitation pulse through spectral or temporal filters. For any ${ }^{2} \Sigma$ vibrational level initially reached by $\mathrm{HO}$ excitation at pressures above 1.5 torr, subsequent rapid vibrational relaxation yields strongest fluorescence from the $v^{\prime \prime}=0 \leftarrow v^{\prime}=0$ transition at $309 \mathrm{~nm}$. In our previous instruments [Hard et al., 1984, 1986, submitted manuscript (1990)] we performed the excitation at $282 \mathrm{~nm}$ because of very large transient background signals with $308 \mathrm{~nm}$ pumping. Even then, off-gating of the PMT dynode chain during the laser pulse was necessary. Although this method worked satisfactorily, the ringing associated with gate turnon was one factor limiting overall system sensitivity. With the Cu-pumped system, PMT dynode gating is not necessary, even with $308 \mathrm{~nm}$ excitation. When ozone was present, our previous systems generated a significant photolytic $\mathrm{HO}$ background in both channels. This background is largely removed by subtraction, since the net HO signal is obtained by chemical modulation. Nevertheless, at high ozone the magnitude of this photolytic background was another significant limitation on system sensitivity. In addition, a small but not insignificant negative offset was produced by the reaction of photolytically produced oxygen atoms with the chemical modulating reagent, isobutane [Hard et al., 1989; submitted manuscript (1990)]. Since both these effects (expressed relative to the response to ambient $\mathrm{HO}$ ) are linear in the laser pulse energy and both of them decrease with increasing wavelength, both are reduced to negligible levels in the 308-nm Cu-vapor laser system.

Construction of copper vapor pumped dye lasers has been reported [Duarte and Piper, 1982, 1984; Amit et al., 1987; Morey, 1980]. Moreover, Stimpfle and Anderson, [1988] and Stimpfle et al., [1989] have used a $17-\mathrm{kHz} \mathrm{Cu}-\mathrm{vapor}$ laser-pumped dye laser at $282 \mathrm{~nm}$ to determine $\mathrm{HO}$ in the lower stratosphere.

The goal of FAGE3 is accurate determination of tropospheric HO. In order to gauge the sensitivity of this new instrument we employed a continuously stirred tank reactor (CSTR) irradiated with UV lamps, as in our previous calibration experiments [Hard et al., 1986]. The CSTR provides a controllable source of $\mathrm{HO}$, and monitoring the consumption of a particular hydrocarbon allows calculation of the HO concentration. Static chamber experiments have been used to measure. $\mathrm{HO}$ reactivities with a number of hydrocarbons, with results that agree with those obtained by 
the discharge-flow and flash-photolysis methods [Doyle et al., 1975; Wu et al., 1976; Atkinson et al., 1979; Finlayson-Pitts and Pitts, 1986]. Static chambers of convenient size are rapidly evacuated by the FAGE sampling nozzles, limiting the fluorescence signal observation times, whereas dynamic chambers (CSTRs) are free of such time limitations.

\section{INSTRUMENT DESCRIPTION}

The dye laser cavity is illustrated in Figure 1. A Metalaser Technologies 20 -W copper vapor laser configured with an unstable resonator cavity pumps the dye laser. The pump laser produces simultaneous pulsed radiation at two wavelengths. A dichroic filter separates the green and yellow outputs for pumping different dye solutions. The green beam $(510 \mathrm{~nm}, \simeq 12 \mathrm{~W}$ ) pumps Rhodamine 590 to provide frequency-doubled output around $282 \mathrm{~nm}$ and the yellow beam ( $578 \mathrm{~nm}, \simeq 5 \mathrm{~W}$ ) pumps Rhodamine 640 to provide doubled output around $308 \mathrm{~nm}$. The 32-mmdiameter $\mathrm{Cu}$ laser beam is first focused by a $155-\mathrm{mm}$ focal length achromatic lens and then further compressed into a narrow line by a $50-\mathrm{mm}$ focal length cylindrical lens for focusing into the dye cell. The dye flow cell is made from a sawn-off quartz microflowmeter cell of $4 \mathrm{~mm} \mathrm{x} 4 \mathrm{~mm}$ interior cross section. A flow restrictor is inserted into the cell to make a flow cross section of $1 \mathrm{~mm} \times 4 \mathrm{~mm}$ at the beam entrance surface. Dye flow rate is about $2.0 \mathrm{~L} / \mathrm{min}$, giving an average linear speed of $8 \mathrm{~m} / \mathrm{s}$ across the region where the laser beam is focused. Dye solutions (about 0.5 $\mathrm{g} / \mathrm{L}$ of Rhodamine $590(6 \mathrm{G})$ or about $0.25 \mathrm{~g} / \mathrm{l}$ of Rhodamine 640 in absolute methanol) are passed through a $0.5-\mu \mathrm{m}$ filter before entering the cell. Final dye concentration is optimized by adding highly concentrated dye solution drop by drop to the dye reservoir while the laser is running to generate maximum output power. Dye temperature is maintained constant by immersing the dye reservoir in a cooled water bath. The dye laser design uses a grazing-incidence grating with intracavity lens [Smith and Dimauro, 1987]; the optical cavity contains a planar end mirror and a $50-\mathrm{mm}$ focal length converging lens between the dye cell and grating. The feed-back reflector can be either a plane mirror or a second grating. A mirror provides a 2 to 3 times higher output power with a wider linewidth (about 0.5 $\mathrm{cm}^{-1}$ at $282 \mathrm{~nm}$ ), while a grating gives a better line width (about $0.18 \mathrm{~cm}^{-1}$ at $282 \mathrm{~nm}$ and $0.25 \mathrm{~cm}^{-1}$ at $308 \mathrm{~nm}$ ) but with lower power. All experimental results presented are done with the grating/grating coupling. The beta barium

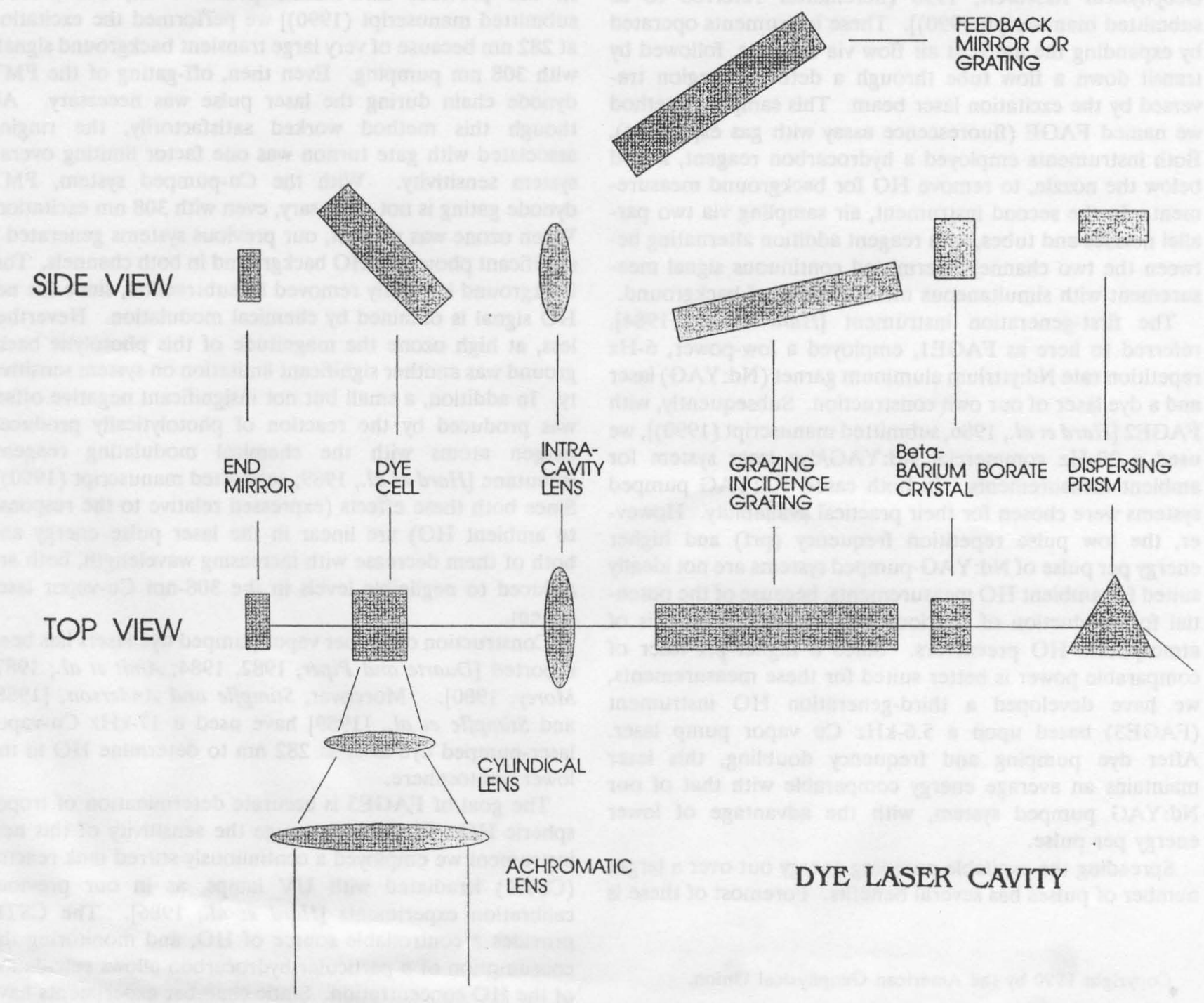

Fig. 1. Dye laser configuration. 
borate frequency-doubling crystal is placed very close to the grating output end, without an extra-cavity focusing lens, and the resulting UV beam is separated from the undoubled output with a 60 degree fused-silica prism.

Wavelength tuning is achieved by rotating the feed-back grating with a $50-\mu \mathrm{m}$ per revolution differential micrometer pushing a 4-inch rotating arm. A computer-driven stepper motor fitted with a gearbox provides a mechanical resolution of 600 steps/revolution. The resulting spectral resolution is approximately $0.003 \mathrm{~cm}^{-1}$ per step. Computer-controlled automatic tuning, using signals from the spectral overlap monitor described below, keeps the laser tuned to the HO absorption transition.

The nozzle/chemical modulation system is as described previously [Hard et al., 1984, 1986, submitted manuscript (1990)], with three modifications. First, single-pass excitation has replaced the former multi-pass White cell. As a result window and cell wall scattering and fluorescence can be better excluded by the use of smaller mask apertures within the cell. Second, the total cell length between Brewster entrance and exit windows (in the direction of the laser beam, perpendicular to the sample flow) is $1.4 \mathrm{~m}$, increasing the distance between the detection zone and the entrance and exit windows, to further exclude window scattering. Third, the HO spectral overlap monitor (formerly a separate cell) has been incorporated into the gas expansion cell by providing a third nozzle $46 \mathrm{~cm}$ away from the two ambient $\mathrm{HO}$ sampling nozzles. A mercury lamp is mounted right outside the third nozzle to provide a constant source of high-concentration $\mathrm{HO}$ (about $10^{9} \mathrm{~cm}^{-3}$ at atmospheric pressure) via water vapor photolysis (source 4 of Hard et al. [1984]). The spectral overlap (or resonance signal) is measured with a RCA 1P28 photomultiplier looking through a narrow-band filter and lens combination. To minimize successive laser pulses striking the same portion of the air mass probed by the previous laser pulse, the UV laser is focused into a slender rectangular cross section of about $1 \mathrm{~mm}$ thickness (in the direction parallel to the sample flow) and $3 \mathrm{~mm}$ width (perpendicular).

Low photon arrival rates allow us to replace the previous signal collection system, consisting of gated PMTs and gated charge integration [Hard et al., 1984, 1986, submitted manuscript (1990)], with a gated photon-counting system. The fluorescence signal is collected by an ungated EMI 9813QKB PMT. The signal coming from the PMT is amplified by a Philips 777 amplifier. Gain in this amplifier is adjusted such that the scattering at 4 torr does not saturate the amplifier, while individual photon pulses are high enough to trigger the discriminator. It was found that the detected electromagnetic interference (EMI) from the copper laser is independent of the PMT bias voltage. The PMT bias voltage is optimized so that photon pulses are greater than the EMI from the $\mathrm{Cu}$ laser, but do not saturate the amplifier. These amplified photon pulses are fed into a $300-\mathrm{MHz}$ discriminator (Phillips 704). The discriminator level is adjusted to at least 1.5 times the positive maximum of the ringing from the copper laser which is minimized by careful shielding of the signal cables and the PMT housing. Output pulses of the discriminator are counted by a gated counter (Tennelec TC532) whose parallel output is wired to the microcomputer. The microcomputer can also reset and start the counters. Gating pulses $300 \mathrm{~ns}$ wide are generated by a pulse generator (BNC 8010 ) triggered by output from a photodiode (MRD 500) looking at part of the scattered dye laser radiation. The gate delay is set at $60 \mathrm{~ns}$ after arrival (at the counter) of the peak of the PMT signal from scattering of dye-laser radiation. Except for the $25 \%$ reduction in isobutane concentration, the chemical modulation cycle is unchanged from that of Hard et al. (submitted manuscript, 1990).

\section{RESULTS AND OBSERVATIONS}

Rhodamine 590 Chloride gives better power conversion efficiency than Rhodamine 590 Perchlorate when pumped by the 511-nm green output of the $\mathrm{Cu}$ laser. The dye laser converts an average power of $12 \mathrm{~W}$ of green light at $511 \mathrm{~nm}$ from the $\mathrm{Cu}$ laser to $1.8 \mathrm{~W}$ of yellow at around $564 \mathrm{~nm}$ and this yellow is frequency doubled to $80 \mathrm{~mW}$ of UV at around $282 \mathrm{~nm}$. It was found that pumping the Rhodamine 590 solution with both green and yellow laser output reduces the dye laser output from that with green pumping alone. About $5 \mathrm{~W}$ of yellow $\mathrm{Cu}$ laser light at $578 \mathrm{~nm}$ can be converted by Rhodamine 640 in the dye laser into $0.5 \mathrm{~W}$ of red at around $616 \mathrm{~nm}$, and then frequency doubled to 20 $\mathrm{mW}$ of UV at around $308 \mathrm{~nm}$. However, during the experiments reported here, the dye laser power at $308 \mathrm{~nm}$ was about $6 \mathrm{~mW}$. Major factors determining the conversion efficiencies are the laser linewidth and the cleanliness of gratings and optics. The quoted laser powers refer to routine operating conditions and linewidth of about 0.3 $\mathrm{cm}^{-1}$.

Figure 2 shows the laser pulse time-profile. Notice that the dye laser output's temporal half width is about $17 \mathrm{~ns}$
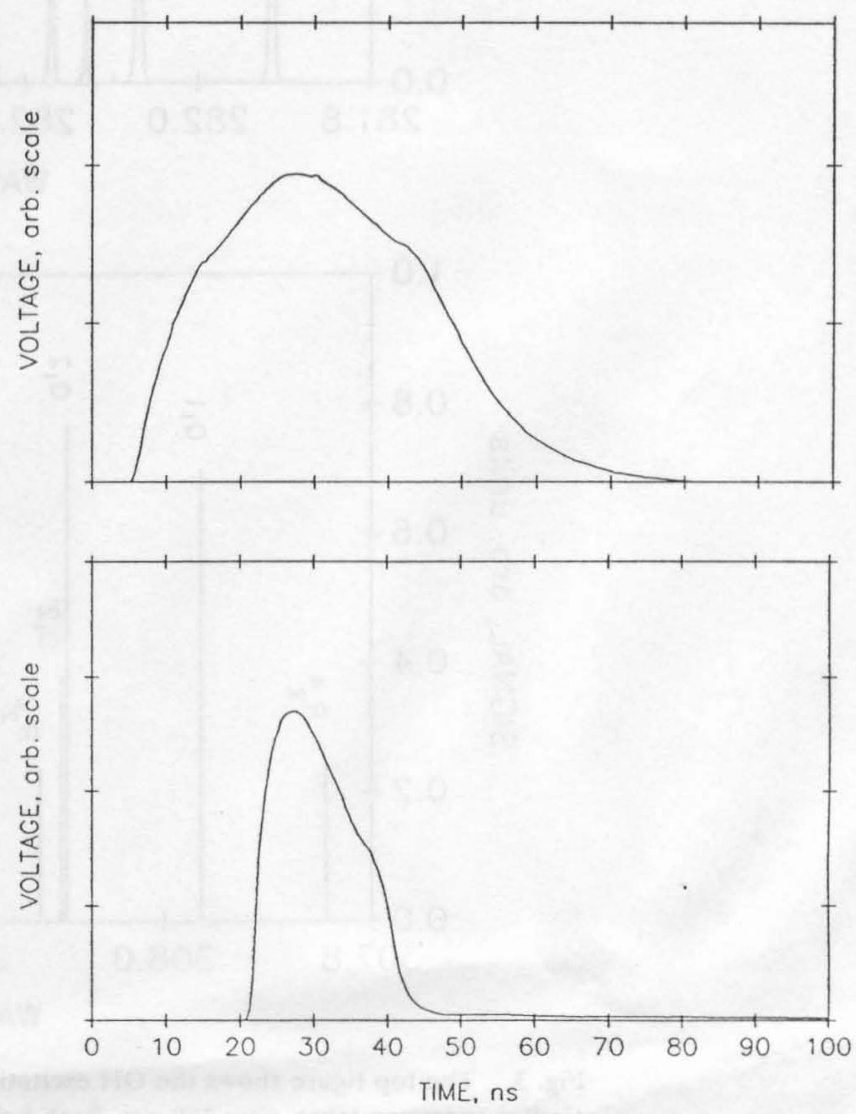

Fig. 2. Temporal laser pulse profiles: top, $\mathrm{Cu}$-vapor pump laser pulse; bottom, dye laser pulse. 
while the input pump laser's is about $40 \mathrm{~ns}$. This shortening of the laser pulse is probably due to thermal lensing in the dye solution [Morey, 1980].

To obtain excitation spectra, $\mathrm{HO}$ is generated by passing pure air of known dewpoint through an annular section around a medium-ozone mercury lamp (BHK OZ4T5), and is expanded in the sampling nozzle to a final pressure of 4 torr. HO excitation lines are monitored by scanning the dye laser while its fluorescence at $309 \mathrm{~nm}$ is measured with the detection system described in the experimental section. Figure 3 shows line scans around $282 \mathrm{~nm}$ and around 308 nm. Using similar HO excitation spectra, we measured linewidths as low as $0.2 \mathrm{~cm}^{-1}$.

Although our previous systems used excitation of $\mathrm{HO}$ at $282 \mathrm{~nm}$ in a multi-pass cell, with fluorescence measurement around $309 \mathrm{~nm}$, the $\mathrm{Cu} /$ dye system allows single-pass excitation of $\mathrm{HO}$ at $308 \mathrm{~nm}$ with improved detection sensitivity.
This approach is preferred here because of reduced ozone photolytic interference (Hard et al., submitted manuscript, 1990); the gated fraction of "nonresonant fluorescence" [Bradshaw et al., 1984] is also greatly reduced; and finally, single-pass excitation permits the use of smaller beam masks, leading to much less stray illumination of the cell walls. The product of the ozone absorption cross section and the $\mathrm{O}\left({ }^{1} \mathrm{D}\right)$ quantum yield [DeMore et al., 1987] at $282 \mathrm{~nm}$ is $2.49 \times 10^{-18}$ $\mathrm{cm}^{2}$, but at $308 \mathrm{~nm}$ it is only $1.05 \times 10^{-19} \mathrm{~cm}^{2}$, about a factor of 24 reduction. Moreover, the peak $\mathrm{HO}$ absorption cross section at $308 \mathrm{~nm}$ is a factor of 3.9 greater than at $282 \mathrm{~nm}$ [McGee and McIlrath, 1984], which cancels the effect of decreased laser power at the longer wavelength.

Since this system is designed to determine ambient $\mathrm{HO}$ radical concentrations, it is most appropriate to calibrate the system against known $\mathrm{HO}$ under simulated ambient conditions [Hard et al., 1984, 1986]. A $0.3-\mathrm{m}^{3}$ flow chamber is
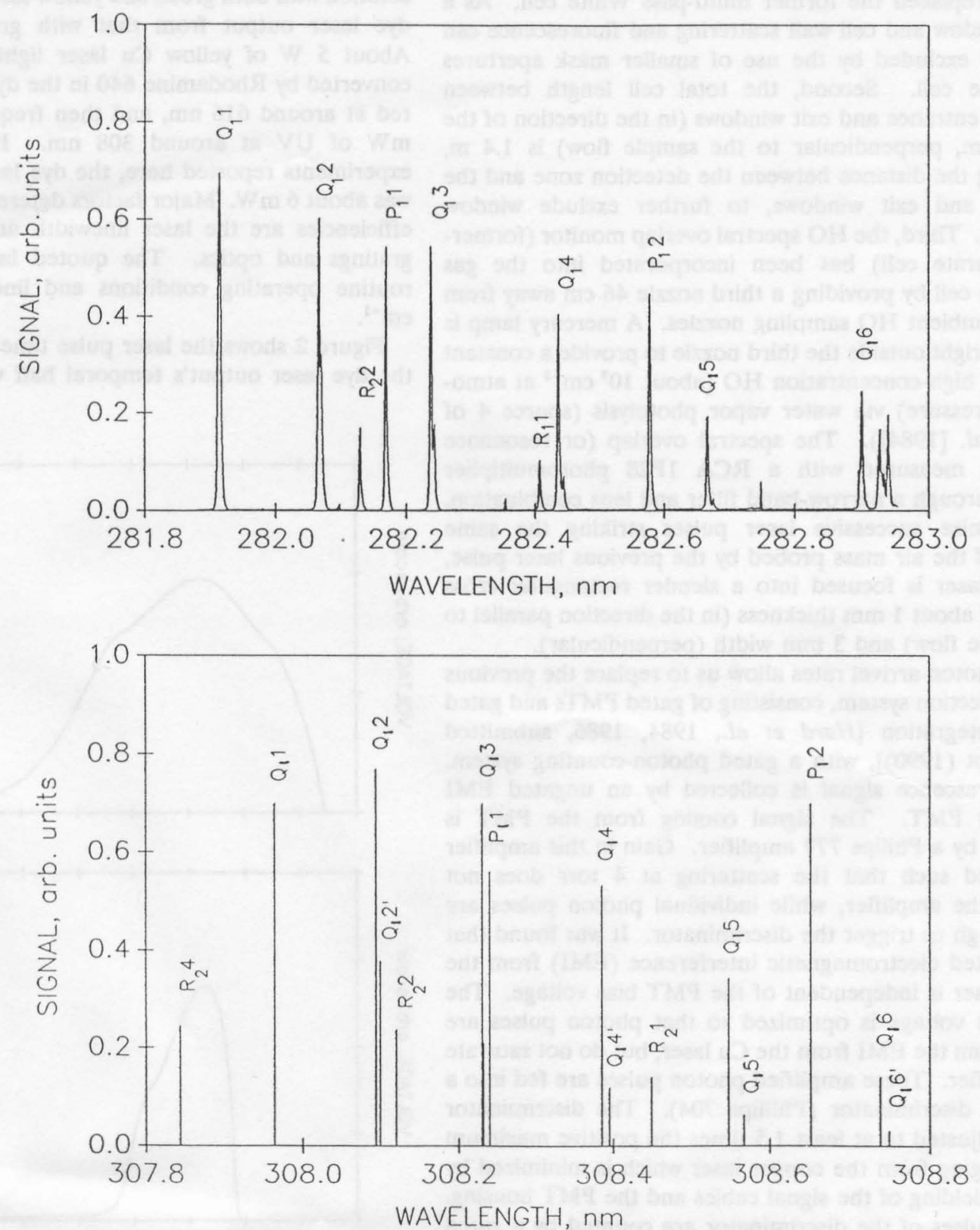

Fig. 3. The top figure shows the $\mathrm{OH}$ excitation spectrum at 4 torr around $282 \mathrm{~nm}$. The lower figure is a similar spectrum taken near $308 \mathrm{~nm}$. Peak heights are nonquantitative. 
constructed with Teflon film. This reactor is surrounded by UV fluorescent lamps, and a small fan inside the bag provides stirred mixing. A steady flow of air of known humidity, with measured flows of $\mathrm{NO}$ and 1,3,5-trimethylbenzene (mesitylene), is fed into this reactor. The trimethylbenzene concentrations at the input and exit from the chamber are monitored by a gas chromatograph (gc) equipped with a photoionization detector. At the same time ozone, $\mathrm{NO}, \mathrm{NO}_{2}$ and water vapor concentrations in the reactor are measured with UV absorption for ozone, chemiluminescence for $\mathrm{NO}$ and $\mathrm{NO}_{2}$, and a dew point hygrometer for water vapor. Upon illumination, $\mathrm{O}_{3}$ and $\mathrm{NO}_{2}$ concentrations increase as $\mathrm{NO}$ is photooxidized under the influence of $\mathrm{HO}$ and the hydrocarbon [Doyle et al., 1975].

Figure 4 illustrates cycles of light and dark in this reaction vessel. Figure $4 a$ represents HO radical concentrations measured by the laser system. HO concentrations calculated from gas chromatographic (gc) data (Figure $4 b$ ) are based on the steady state equation for HO concentration in this system [Hard et al., 1986]:

$$
[\mathrm{HO}]=(k \tau)^{-1}\left\{[\mathrm{HC}]_{\alpha} /[\mathrm{HC}]-1\right\}
$$

where $k$, the rate constant for HO reaction with the hydrocarbon, is equal to $(6 . \pm 1) \times 10^{-11}$ [Perry et al., 1977] and $\tau$ is the reactor residence time. [HC] and [HC] are the inlet and outlet hydrocarbon concentrations, respectively. Since the reactor volume is not accurately known, $\tau$ is measured with the lamps off, by introducing a step change in $[\mathrm{HC}]_{0}$ or $[\mathrm{NO}]_{0}$ in the flowing input to the chamber and fitting the time response of $[\mathrm{HC}]$ or $[\mathrm{NO}]$. When the lamps are turned on, HO measured by the laser system and calculated from the gc data rises to reach a steady state. When the lamps are extinguished, the HO fluorescence signal decreases sharply, followed more slowly by the [HO] trace derived from the hydrocarbon consumption measurement, which has a longer response time. Persistence of $\mathrm{HO}$ in the dark, evident in both FAGE and gc data, is consistent with radical reservoirs near equilibrium during illumination, which undergo net dissociation in the dark, ultimately to produce HO. Chief among these is the rapidly dissociating $\mathrm{HNO}_{4}$ but PAN and perhaps other organic peroxynitrates contribute as well. Typical mechanisms for $\mathrm{HO}_{2}$ production after the lights are extinguished are

$$
\mathrm{HNO}_{4} \rightarrow \mathrm{NO}_{2}+\mathrm{HO}_{2}
$$

and the reaction sequence

$$
\begin{gathered}
\mathrm{CH}_{3} \mathrm{C}(\mathrm{O}) \mathrm{OONO}_{2}(\mathrm{PAN}) \rightarrow \mathrm{CH}_{3} \mathrm{C}(\mathrm{O}) \mathrm{OO}+\mathrm{NO}_{2} \\
\mathrm{CH}_{3} \mathrm{C}(\mathrm{O}) \mathrm{OO}+\mathrm{NO} \rightarrow \mathrm{NO}_{2}+\mathrm{CO}_{2}+\mathrm{CH}_{3} \\
\mathrm{CH}_{3}+\mathrm{O}_{2} \rightarrow \mathrm{CH}_{3} \mathrm{O}_{2} \\
\mathrm{CH}_{3} \mathrm{O}_{2}+\mathrm{NO} \rightarrow \mathrm{NO}_{2}+\mathrm{CH}_{3} \mathrm{O} \\
\mathrm{CH}_{3} \mathrm{O}+\mathrm{O}_{2} \rightarrow \mathrm{CH}_{2} \mathrm{O}+\mathrm{HO}_{2}
\end{gathered}
$$

$\mathrm{HO}_{2}$ is then converted to $\mathrm{HO}$ by NO which continually enters the CSTR:

$$
\mathrm{HO}_{2}+\mathrm{NO} \rightarrow \mathrm{NO}_{2}+\mathrm{HO}
$$

Figure $4 c$ shows the correlation between HO calculated from the gc data (Equation (1)) and the fluorescence signal generated by the laser system during the portion of the experiment when the $\mathrm{HO}$ concentration changes slowly so that the steady state treatment is approximately correct. Equation (1) fails during the rapid concentration changes
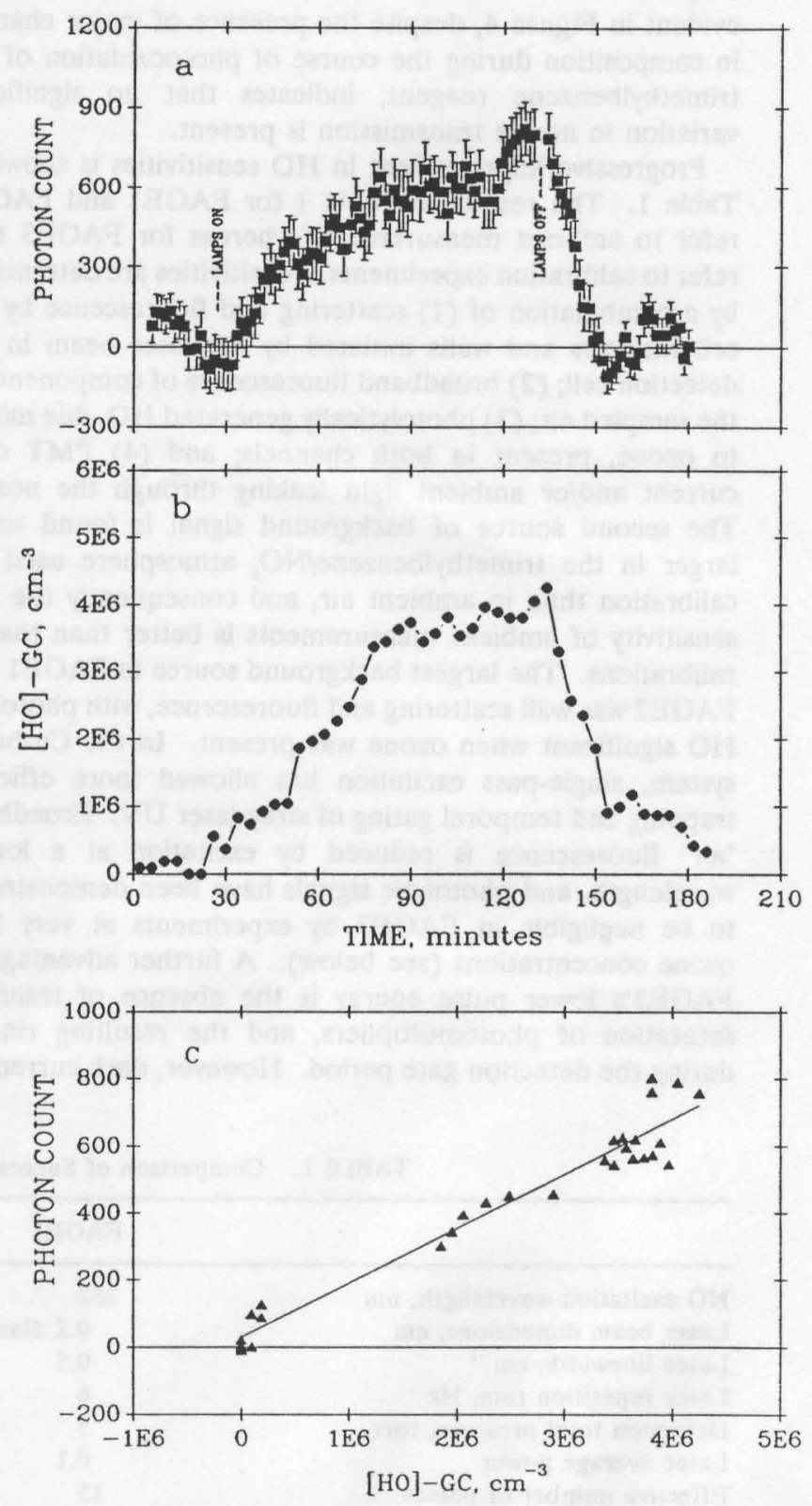

Fig. 4. Hydrocarbon decay calibration experiment. (u): $\mathrm{OH}$ fluorescence measured as sum of the net number of photons collected per $10 \mathrm{~min}$; error bars are \pm 1 times the photuncounting uncertainty, neglecting the covariance of the photon sums subtracted to obtain the net signal. (b): $\mathrm{OH}$ concentisation as calculated from ge measurentent of the 1,3,5-trimethylbenzene depletion. (c): correlation plut between FAGE signals and $H O$ calculated from gc data for the quasi-steady state portion of the HO data. Each lialiE signal is the average of the three points in $(a)$ closest 10 the time of the corresponding gc measurement of $|\mathrm{HO}|$ in $(b)$. The straight line is the least-squares best fit 10 the plotted data. 
associated with the beginning and end of illumination. Full convolution/deconvolution of these data sets is presented elsewhere (O'Brien et al., Fast response HO measurements and hydrocarbon decay, submitted to Journal of Atmospheric Chemistry, 1990).

The chemical transmission of HO by the sampling system, which is implicitly accounted for during external $\mathrm{HO}$ calibration, could potentially vary with the chemical composition of the air mass sampled or with other environmental parameters. Nonetheless, the constant calibration factor evident in Figure 4, despite the presence of major changes in composition during the course of photooxidation of the trimethylbenzene reagent, indicates that no significant variation in nozzle transmission is present.

Progressive improvement in $\mathrm{HO}$ sensitivities is shown in Table 1 . The results in Table 1 for FAGE1 and FAGE2 refer to ambient measurements whereas for FAGE3 they refer to calibration experiments. Sensitivities are determined by a combination of (1) scattering and fluorescence by the cell windows and walls initiated by the laser beam in the detection cell; (2) broadband fluorescence of components of the sampled air; (3) photolytically generated $\mathrm{HO}$, due mostly to ozone, present in both channels; and (4) PMT dark current and/or ambient light leaking through the nozzle. The second source of background signal is found to be larger in the trimethylbenzene/ $\mathrm{NO}_{x}$ atmosphere used for calibration than in ambient air, and consequently the $\mathrm{HO}$ sensitivity of ambient measurements is better than that of calibrations. The largest background source in FAGE1 and FAGE2 was wall scattering and fluorescence, with photolytic $\mathrm{HO}$ significant when ozone was present. In the $\mathrm{Cu}$-based system, single-pass excitation has allowed more efficient trapping and temporal gating of stray laser UV. Broadband "air" fluorescence is reduced by excitation at a longer wavelength, and photolytic signals have been demonstrated to be negligible in FAGE3 by experiments at very high ozone concentrations (see below). A further advantage of FAGE3's lower pulse energy is the absence of transient saturation of photomultipliers, and the resulting ringing during the detection gate period. However, dark current or ambient light are significant in FAGE3, unlike the FAGE2 Nd:YAG system in which these last two background photon sources were inconsequential due to the lower ratio of fluorescence observation time to total time (i.e., duty cycle).

We have developed a detailed chemical-physics model of excitation, saturation, quenching, and fluorescence processes for ambient and laser-generated $\mathrm{HO}$ in our second generation HO system (FAGE2) (Hard et al., submitted manuscript, 1990). Table 2 lists the $\mathrm{Cu} /$ dye system parameters which are appropriate for FAGE3, and the solid curve in Figure 5 shows the predicted dependence of the negative offset on laser flux. Figure 5 assumes $50 \mathrm{ppb} \mathrm{O}_{3}$ and 10 torr $\mathrm{H}_{2} \mathrm{O}$, corresponding to typical ground-level remote tropospheric conditions at mid-latitude. At the vertical line, indicating the laser flux available during the present experiments, the model predicts a net interference of $-2.5 \times 10^{2}$ $\mathrm{HO}$ molecule $\mathrm{cm}^{-3}$.

Since such low concentrations yield no detectable net $\mathrm{HO}$ sign:l, the laboratory interference experiment used dry air, $3.7 \mathrm{ppm} \mathrm{O}_{3}$, and 10 times the standard concentration of isobutane, and detected a net interference of $-(2.7 \pm 1) \times 10^{5}$

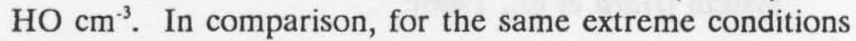
the model yields a net interference of $-1.9 \times 10^{5} \mathrm{HO} \mathrm{cm}$, which is comparable with the experimental result within the measurement uncertainty. Neglecting the latter uncertainty as well as the uncertainty in the model prediction, the experimental result appears to be more negative than the model prediction. If so, a possible cause for this discrepancy is the continuing production of laser-initiated $\mathrm{HO}$ in the flowing sample volume during the interval between laser pulses, with back-diffusion' into the volume excited by the next laser pulse [Smith and Crosley, 1990]. In any case, the chosen experimental cenditions are nearly two decades more severe than the worst conditions encountered in the troposphere. For example, under extreme conditions in the Los Angeles Basin $\mathrm{O}_{3}$ may reach $500 \mathrm{ppb}$; this yields a net interference of $-3.6 \times 10^{3} \mathrm{HO} \mathrm{cm}^{-3}$. Thus the interference levels obtained with $\mathrm{AGE3}$, using chemical modulation, are far below the $10^{5}-10^{7}$ range of daytime HO concentrations at ground level which have been determined by ambient

TABLE 1. Comparison of Successive FAGE Instruments, Referred to FAGE3

\begin{tabular}{lccc}
\hline & FAGE1 & FAGE2 & FAGE3 \\
\hline HO excitation wavelength, $\mathrm{nm}$ & 282 & 282 & 308 \\
Laser beam dimensions, cm & 0.2 diameter & 0.6 diameter & $0.1 \times 0.3$ \\
Laser linewidth, cm ${ }^{-1}$ & 0.5 & 0.3 & 0.3 \\
Laser repetition rate, Hz & 6 & 30 & 5600 \\
Detection total pressure, torr & 5 & 4 & 4 \\
Laser average power & 0.1 & 3 & 1 \\
Effective number of passes & 15 & 0.26 & 1 \\
HO absorption coefficient & 0.26 & 0.35 & 1 \\
Efficiency with respect to saturation & 0.45 & 0.7 & 1 \\
Fluorescence efficiency & 0.7 & 0.67 & 1 \\
Photon collection efficiency & 0.1 & 1.0 & 1 \\
Signal per unit time & 0.012 & 60 & 9 \\
Averaging time, min $^{\mathrm{b}}$ & 107 & $-2 \times 10^{6}$ & $-3 \times 10^{2}$ \\
Zero offset $^{\mathrm{c}}$ & $-4 \times 10^{5}$ & & \\
\hline
\end{tabular}

- Efficiency relative to excitation with laser beam of same pulse energy, with diameter sufficiently large to prevent loss due to stimulated emission (calculated by model).

- At ambient $[\mathrm{HO}]=1 \times 10^{6} \mathrm{molec} \mathrm{cm}^{-3}$, required for photon signal-to-noise ratio equal to 2 .

' In units of ambient [HO] in molec $\mathrm{cm}^{-3}$, at $50 \mathrm{ppb} \mathrm{O}_{3}$ and 10 torr $\mathrm{H}_{2} \mathrm{O}$, using chemical modulation. 
TABLE 2. Quantities Used in Ozone Interference Model, Cu/Dye 308-nm Excitation

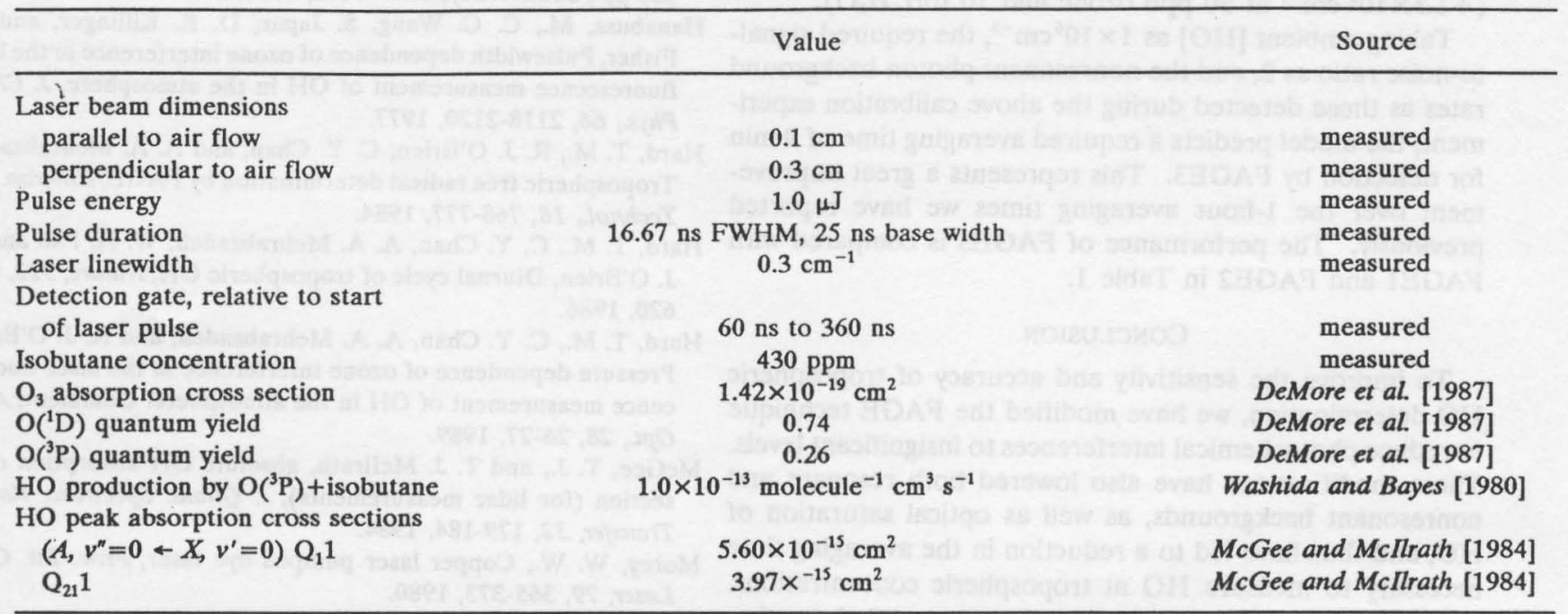

Quantities are listed whose values differ from Table 1 of Hard et al. (submitted manuscript, 1990).

meásurements [Hard et al., 1986; Platt et al., 1988; Felton et -al., 1988].

Also shown in Figure 5 is the predicted interference in FAGE3 using spectral modulation (tuning the laser wavelength on and off the $\mathrm{HO}$ excitation line), in which the isobutane reagent is absent. The spectral modulation offset is larger than that of chemical modulation. The sign of the offset is positive, unlike that in chemical modulation; thus it is less easily distinguished from ambient HO. Nonetheless, at the present value of the flux and under most tropospheric conditions the model suggests that spectral modulation can yield acceptably low interference levels.
Smith and Crosley [1990] have modeled an early version of the system described here which employed pumping at $282 \mathrm{~nm}$. They assumed a $282 \mathrm{~nm}$ laser average power of 90 $\mathrm{mW}$. The 308-nm power employed here was $6 \mathrm{~mW}$. Although Smith and Crosley conclude from their calculations that additional measures are required for suppression of photolytic interference, we find that these measures are not necessary when $\mathrm{HO}$ is excited at $308 \mathrm{~nm}$ using laser average power of the order of 6 to $20 \mathrm{~mW}$. Our model has been tested against the much greater interferences measured with the Nd:YAG/dye system (Hard et al., submitted manuscript, 1990), and for the effects of diffusion in the $\mathrm{Cu} /$ dye case an

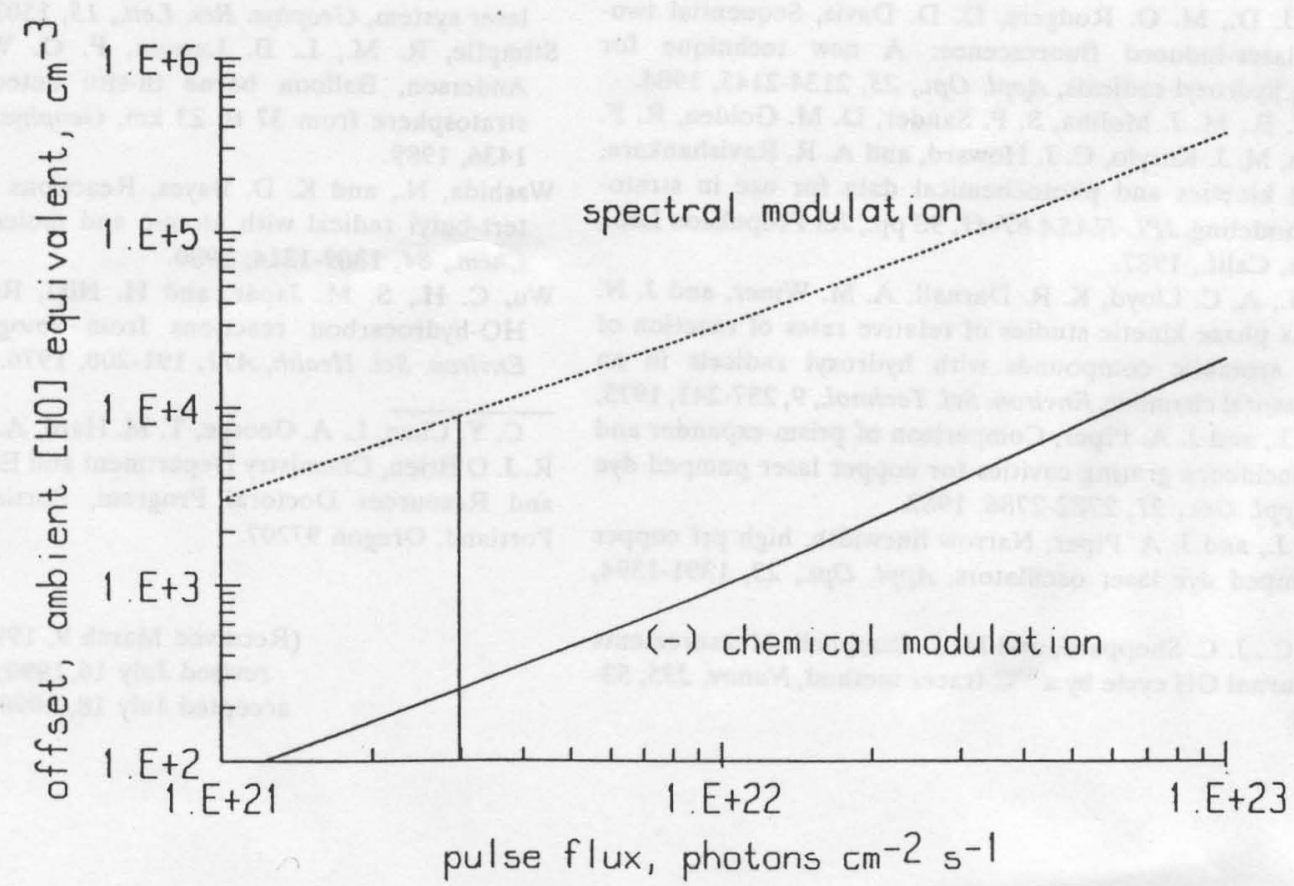

Fig. 5. Net interference versus laser pulse flux, predicted by model. Solid curve: chemical modulation (negative interference, sign reversed for convenience). Dotted curve: spectral modulation. Excitation pulse is positive half of sinewave; flux units refer to squarewave with equal I.WHM and equal area. Vertical line corresponds to flux under conditions in Table 2. 
upper limit to the possible interference has been calculated $\left(+1.3 \times 10^{3} \mathrm{~cm}^{-3}\right.$ at $50 \mathrm{ppb}$ ozone and 10 torr $\left.\mathrm{H}_{2} \mathrm{O}\right)$.

Taking ambient [HO] as $1 \times 10^{6} \mathrm{~cm}^{-3}$, the required signalto-noise ratio as 2 , and the nonresonant photon background rates as those detected during the above calibration experiment, the model predicts a required averaging time of 9 min for detection by FAGE3. This represents a great improvement over the 1-hour averaging times we have reported previously. The performance of FAGE3 is compared with FAGE1 and FAGE2 in Table 1.

\section{CONCLUSION}

To improve the sensitivity and accuracy of tropospheric HO determination, we have modified the FAGE technique to reduce photochemical interferences to insignificant levels. These modifications have also lowered both resonant and nonresonant backgrounds, as well as optical saturation of $\mathrm{HO}$, and thus have led to a reduction in the averaging time necessary to medsure $\mathrm{HO}$ at tropospheric concentrations. The FAGE3 instrument is therefore well-qualified for the study of fast tropospheric photochemistry from either an airborne or ground-based platform.

Acknowledgments. This work was sponsored by National Science Foundation grant ATM-8615163, National Aeronautics and Space Administration grant NAG-1-697, and Environmental Protection Agency grant R81-3012.

\section{REFERENCES}

Amit, M., G. Bialolenker, D. Levron, Z. Bushstein, Refractive index gradients and dye solution flow characteristics in pulsed copper vapor laser pumped dye laser cells, J. Appl. Phys., 63, 1293-1298, 1987.

Atkinson, R., K. R. Darnall, A. C. Lloyd, A. M. Winer, and J. N. Pitts, Kinetics and mechanisms of the reactions of the hydroxyl radical with organic compounds in the gas phase, $A d v$. in Photochem., 11, 375-488, 1979.

Bradshaw, J. D., M. O. Rodgers, D. D. Davis, Sequential twophoton laser-induced fluorescence: A new technique for detecting hydroxyl radicals, Appl. Opt., 23, 2134-2145, 1984.

DeMore W. B., M. J. Molina, S. P. Sander, D. M. Golden, R. F. Hampson, M. J. Kurylo, C. J. Howard, and A. R. Ravishankara, Chemical kinetics and photochemical data for use in stratospheric modeling, JPL-NASA 87-41, 98 pp., Jet Propulsion Lab., Pasadena, Calif., 1987.

Doyle, G. J., A. C. Lloyd, K. R. Darnall, A. M. Winer, and J. N. Pitts, Gas phase kinetic studies of relative rates of reaction of selected aromatic compounds with hydroxyl radicals in an environmental chamber, Environ. Sci. Technol., 9, 237-241, 1975.

Duarte, F. J., and J. A. Piper, Comparison of prism-expander and grazing-incidence grating cavities for copper laser pumped dye lasers, Appl. Opt., 21, 2782-2786, 1982.

Duarte, F. J., and J. A. Piper, Narrow linewidth, high prf copper laser-pumped dye laser oscillators, Appl. Opt., 23, 1391-1394, 1984.

Felton, C. C., J. C. Sheppard, and M. J. Campbell, Measurements of the diurnal $\mathrm{OH}$ cycle by a ${ }^{14} \mathrm{C}$-tracer method, Nature, 335,53 $55,1988$.
Finlayson-Pitts B. J., and J. N. Pitts, Jr., Atmospheric Chemistry, 380 pp., John Wiley, New York, 1986.

Hanabusa, M., C. C. Wang, S. Japar, D. K. Killinger, and W. Fisher, Pulsewidth dependence of ozone interference in the laser fluorescence measurement of $\mathrm{OH}$ in the atmosphere, J. Chem. Phys., 66, 2118-2120, 1977.

Hard, T. M., R. J. O'Brien, C. Y. Chan, and A. A. Mehrabzadeh, Tropospheric free radical determination by FAGE, Environ. Sci. Technol., 18, 768-777, 1984.

Hard, T. M., C. Y. Chan, A. A. Mehrabzadeh, W. H. Pan and R. J. O'Brien, Diurnal cycle of tropospheric OH, Nature, 322, 617$620,1986$.

Hard, T. M., C. Y. Chan, A. A. Mehrabzadeh, and R. J. O'Brien, Pressure dependence of ozone interference in the laser fluorescence measurement of $\mathrm{OH}$ in the atmosphere: Comment, Appl. Opt., 28, 26-27, 1989.

McGee, T. J., and T. J. McIlrath, absolute $\mathrm{OH}$ absorption cross section (for lidar measurements), J. Quant. Spectrosc. Radiat. Transfer, 32, 179-184, 1984.

Morey, W. W., Copper laser pumped-dye laser, Proc. Int. Conf. Laser, 79, 365-373, 1980.

Ortgies, G., K. H. Gericke, and F. J. Comes, Optical measurements of tropospheric hydroxyl with lasers, Z. Naturforsch., 36a, 177-183, 1981.

Perry, R. A., R. Atkinson, J. N. Pitts Jr., Kinetics and mechanism of the gas phase reaction of $\mathrm{OH}$ radicals with aromatic hydrocarbons over the temperature range 296-473 K, J. Phys. Chem., 81, 296-304, 1977.

Platt, U., M. Rateike, W. Junkermann, J. Rudolph, and D. H. Ehhalt, New tropospheric $\mathrm{OH}$ measurements, J. Geophys. Res., 93, 5159-5166, 1988.

Smith, G. P. and D. R. Crosley, A photochemical model of interference effects in laser detection of tropospheric $\mathrm{OH}, \mathrm{J}$. Geophys. Res., in press, 1990.

Smith, R. S., and L. F. Dimauro, Efficiency and linewidth improvements in a grazing incidence dye laser using an intracavity lens and spherical end mirror, Appl. Opt., 26, 855-859, 1987.

Stimpfle, R. M., and J. G. Anderson, In-situ detection of $\mathrm{OH}$ in the lower stratosphere with a balloon borne high repetition rate laser system, Geophys. Res. Lett., 15, 1503-1506, 1988.

Stimpfle, R. M., L. B. Lapson, P. O. Wennberg, and J. G. Anderson, Balloon borne in-situ detection of $\mathrm{OH}$ in the stratosphere from 37 to $23 \mathrm{~km}$, Geophys. Res. Lett., 16, 14331436, 1989.

Washida, N., and K. D. Bayes, Reactions of isobutane and the tert-butyl radical with atomic and molecular oxygen, J. Phys. Chem., 84, 1309-1314, 1980.

Wu, C. H., S. M. Japar, and H. Niki, Relative reactivities of HO-hydrocarbon reactions from smog reactor studies, $J$. Environ. Sci. Health, A11, 191-200, 1976.

C. Y. Chan, L. A. George, T. M. Hard, A. A. Mehrabzadeh, and R. J. O'Brien, Chemistry Department and Environmental Sciences and Resources Doctoral Program, Portland State University, Portland, Oregon 97207.

(Received March 9, 1990; revised July 16,1990; accepted July 18,1990 .) 